\title{
Timing of Surgery and Complications of Acute Appendicitis: A Retrospective Study
}

\section{Ricardo Purchio Galletti ${ }^{1}$, Vinicius Oliveira Fernandes ${ }^{1}$, Neil Ferreira Novo², Willy Marcus França ${ }^{3^{*}}$}

\author{
${ }^{1}$ Faculty of Medical Science and Health, PUC/SP (FCMS, PUC/SP), Sorocaba, Brazil \\ ${ }^{2}$ Department of Medicine, Service of Statistical Studies of PUC/SP, Sorocaba, Brazil \\ ${ }^{3}$ Laboratory of Surgery Technique and Experimental Surgery of FCMS, PUC/SP, Faculty of Medical Science and Health, \\ Sorocaba, Brazil \\ Email: *willy@drwilly.com.br
}

How to cite this paper: Galletti, R.P., Fernandes, V.O., Novo, N.F. and França, W.M. (2019) Timing of Surgery and Complications of Acute Appendicitis: A Retrospective Study. Surgical Science, 10, 147-153. https://doi.org/10.4236/ss.2019.105018

Received: April 5, 2019

Accepted: May 17, 2019

Published: May 20, 2019

Copyright (c) 2019 by author(s) and Scientific Research Publishing Inc. This work is licensed under the Creative Commons Attribution International License (CC BY 4.0).

http://creativecommons.org/licenses/by/4.0/

\section{cc) (i) Open Access}

\begin{abstract}
Introduction: Acute appendicitis (AA) is the most frequent surgical condition of the abdomen during childhood. Its clinical presentation in children under 5 may be atypical and thus causes a delay in diagnosis, which often leads to complications such as perforation and peritonitis. Patients with unperforated AA at hospital admission may have their surgery postponed up to 24 hours while antibiotics are initiated without significant increase in complications, instead of undergoing immediate surgery. Immediate surgery to prevent complications has been questioned. Delaying surgery in patients admitted to hospital with AA has not increased the risk of perforation. Objective: To determine the impact of timing of surgery of patients with AA admitted to our Pediatric Surgery Ward of the Sorocaba Hospital Complex of the Medical Science and Health Faculty (CHS-PUC/SP) on the rate of complications (perforation, peritoneal drainage and infection of the surgical wound). Methods: We reviewed the records of 195 children aged 4 to 12 years, admitted between 2010 and 2014. They were separated in 2 groups according to timing of surgery under 7 hours (group A) and 7 to 24 hours (group B) and had their rate of complications (infection of the surgical wound, drainage and perforation (grade IV) assessed. Results: Ninety-seven children underwent surgery less than 7 hours after admission (group A) and 98 children were operated between 7 and 24 hours after admission (group B). Groups A and B had no significant difference regarding the rates of wound infection $(p=0.2277)$, peritoneal drain insertion $(p=0.4085)$ or perforation $(p=0.7125)$. Conclusions: In our study, timing of surgery for AA had no impact on the occurrence of complications, such as infection of the surgical wound, peritoneal drainage or perforation.
\end{abstract}




\section{Keywords}

Acute Appendicitis, Intrabdominal Abscess, Antibiotic Therapy, Appendix Perforation

\section{Introduction}

Acute appendicitis is the most frequent surgical condition of the abdomen in childhood. Children under 5 years of age may have AA with a typical clinical presentation which causes a delay in diagnosis that often leads to increased rates of complications, such as appendix perforation and peritonitis (82\% of the cases), and increases both morbidity and mortality rates in this age group [1]. Recent studies have compared the efficacy of antimicrobial therapy with multiple drugs (ampicillin, clindamycin and gentamicin) or single drugs (piperacillin/tazobactam) in preventing post-operative complications and reducing costs [2] [3].

According to Pérez-Martinez et al., 2005, although uncomplicated AA may still be considered an emergency, delaying surgery up to 18 hours after hospital admission does not increase the rate of complications [4]. Similarly, a study by Henry et al., 2007, has shown that non-surgical management of perforated AA was associated with low rates of complications and shorter hospitalization, when compared to matched controls [5].

Yardeni et al. (2004), recommended that in non-perforated AA, antibiotic treatment should be initiated when surgery is delayed 2 to 6 hours after admission. That way, surgery may be postponed within 24 hours of admission with no significant increase in complications, duration of surgery and hospitalization [6]. More recently, the benefits of immediate surgery for AA have been questioned. Teixeira et al. (2012), have shown that in patients with non-perforated AA, delaying surgery significantly increased the rate of surgical wound infection but not the risk of perforation [7].

Other authors have studied the role of prolonged timing of hospital arrival and delayed surgery after admission as independent predictive factors of complications such as perforation [8]. Some authors suggest that tachycardia at admission in patients with AA may be significant as a predictive factor of higher risk of perforation [8].

InAA patients who are treated conventionally, time seems to be the most important element in AA progression towards complete obstruction and perforation [9]. Patients at higher risk of perforation may undergo surgery sooner or receive pre-operative antimicrobial therapy. But it appears most likely that perforation occurs before hospital admission and is not time-dependent [9].

Other researchers have reported no significant increases in the rate of perforation and infection of the surgical wound when appendectomy was delayed. However, a higher risk of wound infection was associated with prolonged duration of 
symptoms [10]. In a multicenter study with 1388 patients, infection of the surgical wound occurred in $5.7 \%$ of the patients with complicated AA (perforation and gangrene) and in $1.2 \%$ of the patients with uncomplicated AA. Timing of surgery did not significantly increase the occurrence of such complications-11.5 hours ( $6.4-14.7 \mathrm{~h}$ ) versus 9.7 hours (5.8 - 15.6 h, $p=0.36)$ [11].

In a recent study by Abbas et al. (2016), with children with AA, delayed surgical treatment did not increase the rate of post-operative complications and infection of the surgical wound [12].

In our Pediatric Surgery ward, some elements appeared to play an important role in the development of complications such as perforation, surgical wound infection and prolonged hospitalization in AA patients: the duration of symptoms, timing of arrival at our referral hospital from different services of origin and timing of surgery after admission [13] [14] [15] [16].

The objective of our study was to evaluate the rate of complications (perforation, use of peritoneal drainage and infection of the surgical wound) related to timing of surgery in AA patients admitted to the Pediatric Surgery ward of the Sorocaba Hospital Complex of the Medical Science and Health Faculty (CHS-PUC/SP), at Sorocaba, Brazil.

\section{Methods}

We studied the hospital records of 195 children aged 4 - 12 years, admitted to the Regional Hospital of the Sorocaba Hospital Complex between January 2010 and December 2014 with diagnosed AA, who underwent surgery and were hospitalized at the Pediatric Surgery ward.

The following data were collected from the patient's record at admission: age, gender, clinical presentation, physical examination findings, duration of symptoms and timing of hospital admission and timing of surgery. In addition, we also collected post-operative data, such as the presence of perforation (appendicitis stage IV), infection of the surgical wound with the presence of abscess and insertion of peritoneal drains.

Figure 1 shows the different stages of Acute Appendicitis: (A) initial inflammatory process with edema of the appendix (stage I), which progresses to (B) ecchymosis of the appendix serosa (stage II); then (C) distal necrosis without perforation (stage III) and eventually perforation (D) of the appendix wall (stage IV).

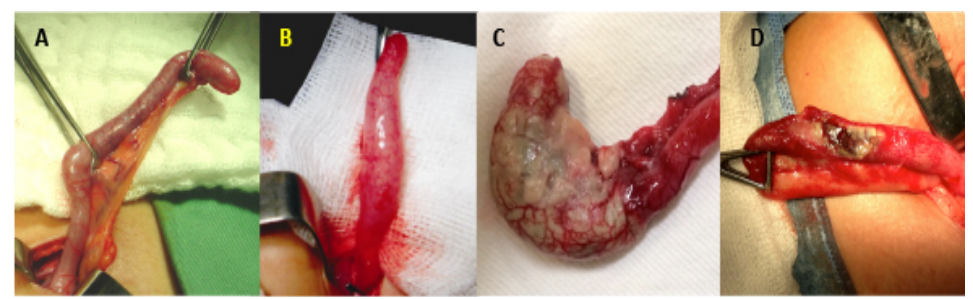

Figure 1. Intra-operative images of Acute Appendicitis stages: (A) stage I; (B) stage II; (C) stage III and (D) stage IV. 
We employed descriptive analysis to characterize our study sample according to different continuous variables, such as age, gender, duration of symptoms, timing of surgery and others.

In other to study all those nominal data and compare them between the groups it will be used $C h i$-square test and adopted level of significance of $5 \%$ ( $p$ $<0.05)$.

\section{Results}

One hundred and ninety-five patients had their hospital records analyzed for this study. They were separated in two groups: group A included 97 patients (49.74\%) who had undergone appendectomy within 7 hours of hospital admission; and group B with 98 patients (50.26\%) who had had appendectomy 8 hours or more after admission.

One hundred and thirty-six (70\%) patients of the total study sample were male. In this group, 65 children (47.79\%) had undergone surgery within 7 hours of admission and 71 boys (52.2\%) had had appendectomy over 7 hours after admission. There were 59 female patients (30\%) in the study sample and 32 of them (48.4\%) had undergone surgery within 7 hours and 27 (51.6\%) had had appendectomy more than 7 hours after admission (Table 1).

None of the 195 patients in our sample had AA stage I. Twelve patients (6\%) with AA stage II had had surgery within 7 hours, whereas 14 (7.2\%) had had surgery after 7 hours or more, with a total of 26 in stage II (13.3\%). In a total of 78 children (40\%) with stage III AA, 37 (19\%) patients with AA stage III had undergone surgery before 7 hours and 41 (21\%) had undergone surgery after 7 hours or more. Finally, among 91 patients (46.7\%) who had AA stage IV, 48 (24.6\%) had undergone appendectomy within 7 hours and 43 (22\%) had undergone appendectomy after 7 hours or more (Table 2).

Chi-square analysis of these data showed no significant differences between different AA stages $(p=0.7125)$.

Complications such as intrabdominal abscess emerged in 25 patients of group A $(25.77 \%)$, and in 18 patients in group B (18.36\%), as shown in Table 3 . In the group A 34 (35.55\%) patients needed peritoneal drainage whereas 41 (41.83\%) in group B. Chi-square analysis showed no significant difference between the groups $(p=0.4085)$ ('Table 3$)$.

Chi-square analysis showed no significant difference between both groups regarding the analyzed variable (surgical wound infection), with $p=0.2277$.

Table 1. Distribution of study patients according to gender and timing of surgery.

\begin{tabular}{cccc}
\hline AA $(\mathrm{n}=200)$ & $\Delta \mathrm{T}<7$ hours & $\Delta \mathrm{T}>7$ hours & Total (n\%) \\
Male & $65(47.8 \%)$ & $71(52.2 \%)$ & $136(70 \%)$ \\
Female & $32(54.2 \%)$ & $27(45.8 \%)$ & $59(30 \%)$ \\
Total & $97(49.7 \%)$ & $98(50.3 \%)$ & $195(100 \%)$
\end{tabular}


Table 2. Distribution of study patients according to appendicitis stage and timing of surgery.

\begin{tabular}{cccc}
\hline AA $(\mathrm{n}=\mathbf{1 7 9})$ & $\Delta \mathrm{T}<\mathbf{7 \text { hours }}$ & $\Delta \mathrm{T}>\mathbf{7}$ hours & Total \\
\hline Stage I & 0 & 0 & 0 \\
Stage II & $12(6.2 \%)$ & $14(7.2 \%)$ & $26(13.3 \%)$ \\
Stage III & $37(19 \%)$ & $41(21 \%)$ & $78(40 \%)$ \\
Stage IV & $48(25 \%)$ & $43(22 \%)$ & $91(47 \%)$ \\
Total & $\mathbf{9 7 ( 4 9 . 7 \% )}$ & $98(50.3 \%)$ & 195 \\
\hline
\end{tabular}

Chi-square analysis: $p=0.7125$.

Table 3. Patients with post-operative complications in groups A and B.

\begin{tabular}{cccc}
\hline \multicolumn{2}{c}{ AA (n = 195) } & \multicolumn{2}{c}{ Complications/wound infection } \\
\cline { 3 - 4 } & $97(49.74 \%)$ & $25(25.8 \%)^{*}$ & Peritoneal Drainage \\
\hline Group A $(<7 \mathrm{~h})$ & $98(50.26 \%)$ & $18(18.4 \%)^{*}$ & $34(35.05 \%)^{*}$ \\
Group B ( $>7 \mathrm{~h})$ & 195 & $43(\mathbf{2 2 . 0 5 \% )}$ & $41(41.84 \%)^{*}$ \\
Total & $195 \%(38.46 \%)$ \\
\hline
\end{tabular}

*Percentages are related to a total number in each group.

\section{Discussion}

In patients with acute appendicitis, timing of surgery does not seem to increase the risk of complications like perforation and wound infection [1] [2]. Employing medical imaging techniques such as ultrasound and computed tomography may be valuable to perform an early diagnosis and to guide treatment in order to prevent complications, regardless of the timing of surgery [2] [3].

Acute appendicitis, even when uncomplicated, is still considered an emergen$\mathrm{cy}$, though some authors have reported that postponing surgery up to 18 hours after admission does not increase the rate of complications [4] [5]. The same was concluded by Yardeni et al. (2004), that showed no significant difference regarding length of hospital stay, hospitalization costs and rate of perforation between children submitted to appendectomy within 6 hours of admission $(n=38)$ and those who had undergone surgery after that period of admission [6] [7].

Despite conventional treatment of AA suggests that time could be the most important factor in the progression of AA towards complications such as perforation without immediate intervention, it seems to happen more likely before hospital admission and is in fact not related to timing [9].

At first glance, timing of patients' referral from different levels of assistance and other nearby cities to our Emergency Room as well as timing of surgery after admission in the Pediatric ward could play an important role in the increased rate of morbidity and complications such as perforation and surgical wound infection [10] [12] [13]. Li J et al. (2019), suggested that "delay did not increase the risk of complicated appendicitis but was associated with a slightly increased risk of surgical site infection" [17]. 
The results of the present study are consistent with previous studies described. We found no significant difference between groups A and B regarding the occurrence of post-operative complications, such as surgical wound infection ( $p=$ $0.2277)$, the need of peritoneal drainage $(p=0.4085)$ or AA stage IV (perforation; $p=0.7125)$.

\section{Conclusion}

Variations in timing of surgery for AA led to no significant differences on the development of complications such as surgical wound infection, peritoneal drain insertion or perforation between the two groups.

\section{Conflicts of Interest}

The authors declare no conflicts of interest regarding the publication of this paper.

\section{References}

[1] Morrow, S.E. and Newman, K.D. (2007) Current Management of Appendicitis. Seminars in Pediatric Surgery, 16, 34-40. https://doi.org/10.1053/j.sempedsurg.2006.10.005

[2] Lund, D.P. and Murphy, E.U. (1994) Management of Perforated Appendicitis in Children: A Decade of Aggressive Treatment. Journal of Pediatric Surgery, 29, 1130-1134. https://doi.org/10.1016/0022-3468(94)90294-1

[3] Nadler, E.P., Reblock, K.K., Ford, H.R. and Gaines, B.A. (2003) Monotherapy versus Multi-Drug Therapy for the Treatment of Perforated Appendicitis in Children. Surgical Infections, 4, 327-333. https://doi.org/10.1089/109629603322761382

[4] Pérez-Martinez, A., Conde-Cortés, J., Matínez-Bermeio, M.A., Bento-Bravo, L., Busto-Aguirreureta, N. and Goñi-Orayen, C. (2005) Programmed Surgery for Acute Appendicitis. Cirugía Pediátrica, 18, 109-112.

[5] Henry, M.C., Gollin, G., Islam, S., Sylvester, K., Walker, A., Silverman, B.L. and Moss, R.L. (2007) Matched Analysis of Nonoperative Management vs Immediate Appendectomy for Perforated Appendicitis. Journal of Pediatric Surgery, 42, 19-24. https://doi.org/10.1016/j.jpedsurg.2006.09.005

[6] Yardeni, D., Hirschl, R.B., Drongowski, R.A., Teitelbaum, D.H., Geiger, J.D. and Coran, A.G. (2004) Delayed versus Immediate Surgery in Acute Appendicitis: Do We Need to Operate during the Night? Journal of Pediatric Surgery, 39, 464-469. https://doi.org/10.1016/j.jpedsurg.2003.11.020

[7] Teixceira, P.G., Sivrikoz, E., Inaba, K., Talving, P., Lam, L. and Demetriades, D. (2012) Appendectomy Timing. Annals of Surgery, 256, 538-543. https://doi.org/10.1097/SLA.0b013e318265ea13

[8] Kearney, D., Cahill, R.A., O’Brien, E., Kirwan, W.O. and Redmond, H.P. (2008) Influence of Delays on Perforation Risk in Adults with Acute Appendicitis. Diseases of the Colon \& Rectum, 51, 1823-1827. https://doi.org/10.1007/s10350-008-9373-6

[9] Serres, S.K., Cameron, D.B., Glass, C.C., Graham, D.A., Zurakowski, D., Karki, M., Anandalwar, S. and Rangel, S.J. (2017) Time to Appendectomy and Risk of Complicated Appendicitis and Adverse Outcomes in Children. JAMA Pediatrics, 171, 740-747. https://doi.org/10.1001/jamapediatrics.2017.0885 
[10] Boomer, L.A., Cooper, J.N., Deans, K.J., Minneci, P.C., Leonhart, K., Diefenbach, K.A., Kenney, B.D. and Besner, G.E. (2014) Does Delay in Appendectomy Affect Surgical Site Infection in Children with Appendicitis? Journal of Pediatric Surgery, 49, 1026-1029. https://doi.org/10.1016/j.jpedsurg.2014.01.044

[11] Boomer, L.A., Cooper, J.N., Anadalwar, S., Fallon, S.C., Ostlie, D., Leys, C.M., Minneci, P.C., et al. (2016) Delaying Appendectomy Does Not Lead to Higher Rates of Surgical Site Infections. Annals of Surgery, 264, 164-168.

https://doi.org/10.1097/SLA.0000000000001396

[12] Abbas, P.I., Peterson, M., Stephens, L.J., Rodrigues, J.R., Lee, T.C., Brandt, M.L. and Lopez, M.E. (2016) Evaluating the Effect of Time Process Measures on Appendectomy Clinical Outcomes. Journal of Pediatric Surgery, 51, 810-814. https://doi.org/10.1016/j.jpedsurg.2016.02.027

[13] Eldar, S., Nash, E., Sabo, E., Matter, I., Kunin, J., Mogilner, J.G. and Abrahamson, J. (1997) Delay of Surgery in Acute Appendicitis. The American Journal of Surgery, 173, 194-198. https://doi.org/10.1016/S0002-9610(96)00011-6

[14] Shin, C., Roh, Y. and Kim, J. (2014) Delayed Appendectomy versus Early Appendectomy in the Treatment of Acute Appendicitis: A Retrospective Study. World Journal of Emergency Surgery, 9, 8-13. https://doi.org/10.1186/1749-7922-9-8

[15] Bonadio, W., Rebillot, K., Ukwuoma, O., Saracino, C. and Iskhakov, A. (2017) Management of Pediatric Perforated Appendicitis. The Pediatric Infectious Disease Journal, 36, 937-941. https://doi.org/10.1097/INF.0000000000001025

[16] Beres, A., Al-Abbad, S. and Puliglanda, P.S. (2010) Appendicitis in Northern Aboriginal Children: Does Delay in Definitive Treatment Affect Outcome? Journal of Pediatric Surgery, 45, 890-893. https://doi.org/10.1016/j.jpedsurg.2010.02.008

[17] Li, J., Xu, R., Hu, D.M., Zhang, Y., Gong, T.P. and Wu, X.L. (2019) Effect of Delay to Operation on Outcomes in Patients with Acute Appendicitis: A Systematic Review and Meta-Analysis. Journal of Gastrointestinal Surgery, 23, 210-223. https://doi.org/10.1007/s11605-018-3866-y 